\title{
ELIMINATING WRONG SPOT WELDING BY ROBOTS IN PRODUCTION LINE
}

\section{P. VIGNESH ${ }^{1}$, M. PARIVALLAL ${ }^{2}$, D. MOHANKUMAR ${ }^{3}$ \& NAVEENCHANDRAN. P $^{4}$}

${ }^{I}$ Assistant Professor, Department of Mechanical Engineering, Indira Institute of

Engineering and Technology, Pandur, Thiruvallur, Tamil Nadu, India

${ }^{2}$ Associate Professor, Department of Mechanical Engineering, Indira Institute of

Engineering and Technology, Pandur, Thiruvallur, Tamil Nadu, India

${ }^{3}$ Assistant Professor, Department of Automobile Engineering, Bharath Institute of Higher

Education and Research, Tamil Nadu, India

${ }^{4}$ Professor, Department of Automobile Engineering, Bharath Institute of Higher

Education and Research, Tamil Nadu, India

\section{ABSTRACT}

The main objective of our project is to reduce the false seam joints. There are many important issues, such as waiting for a lost robot, checking individual parts, unnecessary manual nutrition and increasing the cycle time of this soldering joint. When the cycle times are getting longer, the company's revenue decreases accordingly. Many large manufacturing companies have discovered this false weld defect at the end of the painting. In other words, in the field of quality, if an error is detected in the material during the inspection, it is completely lost. The content is processed or replayed until the entire row is stopped and the entire row is off. This manufacturer proves a defect in two ways. One is with a laser and another by ultrasound. Test equipment is placed in the mass zone for testing purposes. You can get $99 \%$ of the correct output. However, this is not necessary if the error is completely lost in the final stage, if the economic cost of these devices is high and if the skilled worker has to deal with this problem, our project, therefore, will use another device. To avoid this error in the initial phase, we found that the weld at the main point increased due to the poor solution in the drawer. Using simple Plc coding methods, we use light and automation sensors to develop devices that detect seat position changes. We use the Six Sigma method to eliminate this error. It is possible to eliminate the risk of wrong place welding and reduce the output defect by $100 \%$.

KEYWORDS: Spot Welding, Sig Sigma, Fish Bone Diagram, Hand Sketch, Nx-Cad Sketch, PLC Ladder \& Prototype

Received: May 13, 2019; Accepted: Jun 03, 2019; Published: Jul 22, 2019; Paper Id.: IJMPERDAUG2019123

\section{INTRODUCTION}

It is one of the most advanced applications in the manufacture of place welding robots. Automatic resistance, the spot welding speed accuracy [1-5], efficiency and cost savings are mainly recognized in the automotive industry. But the industry needs the most mature solution to continue growing. End users, including experts from three major car manufacturers, are looking for unprecedented speed and access in robotic applications. The engineer is lighter than the modular system, requiring longer cycle time and better tool arm (EOAT), and suppliers meet the design requirements of the automotive. We need more new spot welding robots [6-8].

Motoman has announced a dedicated welding controller (ES 165 and ES 200165200 kg) - Figure 3. The robot is designed for use (air, water, energy). Cable by arm and robot wrist. The standard cable kit is compatible 
with a servo or air gun. Internal extraction eliminates the need for support and the outer band rotation [11-16].

Chris Anderson of Motoman Inc. said: "The robot engine is self-developed and provides long-term reliable service with an average failure of 24,000 hours." Quick connectors are easy to replace and preventive maintenance can be designed using the main components of a robot engine. "

The offline program can be used directly, without interruption due to a cable interruption. The cables are integrated into thin arm configurations, which provide easy access to robotic manufacturer warranty periods. Limited space and original equipment, such as field extraction methods [9-10].

The most common causes of robotic welding robots are the torches and cables (robot devices) used to handle firearms. The dynamic movement of robot movements causes fatigue and downtime, and spot welding guns may experience damage damage. Robotic equipment is minimized because the control panel only requires a device to maintain air energy and signal by placing a torch on a fixed support [17-21]. The Crawford EOA system explains that robots are more robust and require more time.

\section{PROBLEM DESCRIPTION}

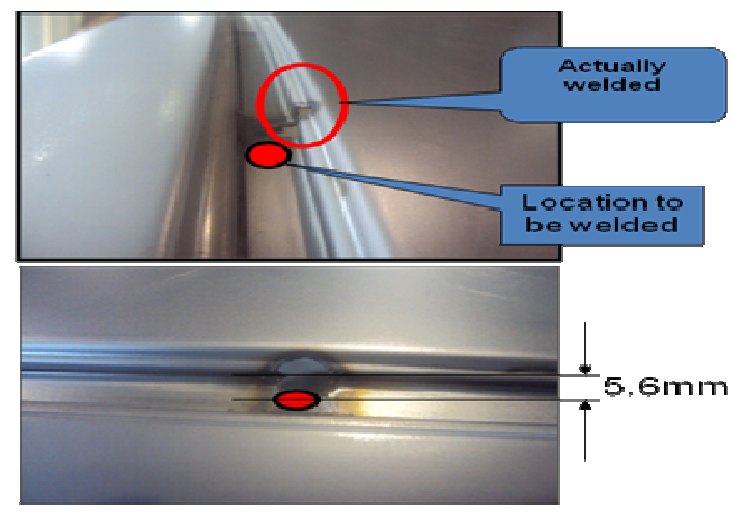

Figure 1: Before Installation of BSC Device

Nissan factory opened in May 2016. The company started production of cars such as a Renault dust collector, Reynolds, Kara, Nissan Terrano and Nissan Tiana. This vehicle is an SUV model. We will develop production lines and production areas to produce such vehicles [32-38]. In June 2017, the alliance decided to produce a car for the Nissan Maikura. This Nissan Maikura size is smaller than $4 \times 4$ vehicles.

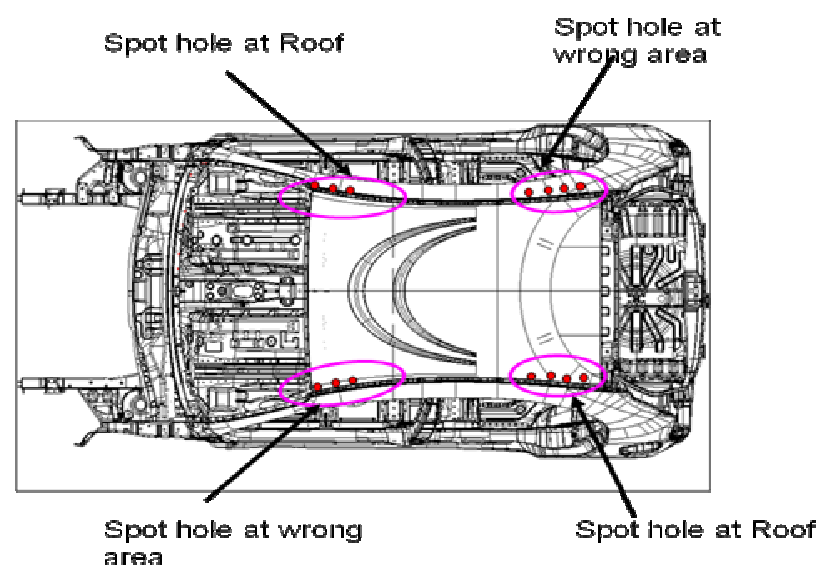




\section{Figure 2: Wrong Spot Welding Areas}

Nissan factory opened in May 2016. The company started production of cars such as Renault dust collector [29-31], Reynolds Kara, Nissan Terrano and Nissan Tiana. This vehicle is an SUV model. We will develop production lines and production areas to produce such vehicles. In June 2017, the alliance decided to produce a car for the Nissan Maikura. This Nissan Maikura size is smaller than 4x4 vehicles [22-28].

In the last three years, from mid-2017 to mid-2015, we experienced special damage during bodybuilding. It is an improper place welding. The welding spot is not in the right position. For this problem, the company has a major problem: lost time, robot time and replacement cost.

Inspecting problem

- Inspect this problem,

- Cause and effect of the problem,

- How to rectify the problem,

- Management theories for analyzing the problem.

- Design and fabrication of the problem detecting device.

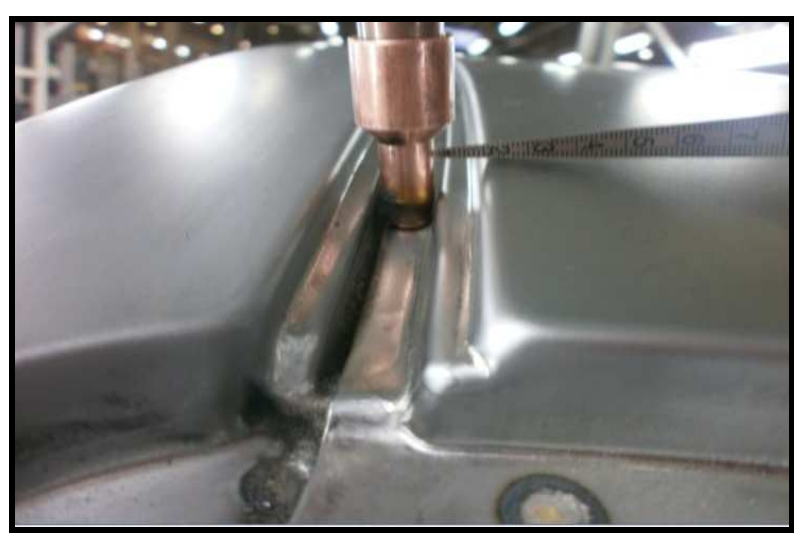

Figure 3: Problem Description
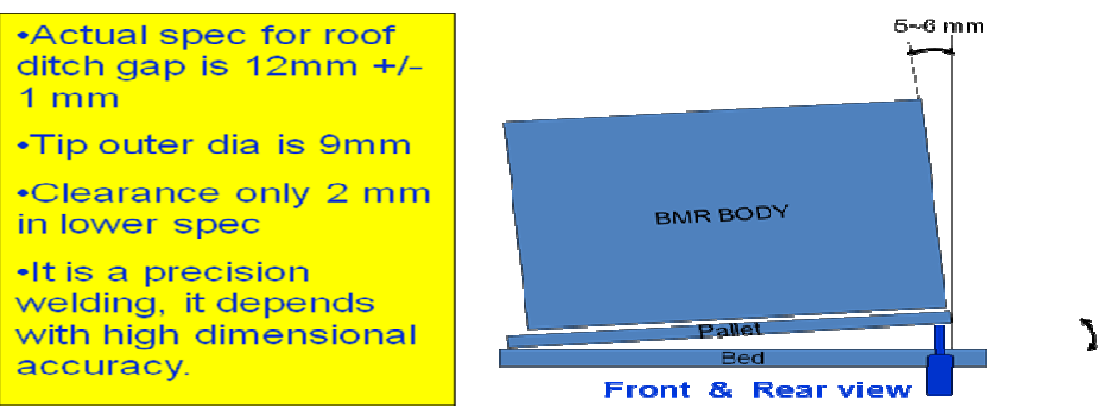

Figure 4: Errors in Body Seating

Our fault tracking system must have nominal size, minimum maintenance, space savings, accuracy, short cycle time and can operate automatic boats without power. We determined that it was not in the right position in a lower platform blockade blockade. Due to this change, the roof has deviated from the entire area. This change causes a place 
welding error. The robot is only programmed to be welded to the roof. It is unknown whether the weld is made in the right position or not.

We decided to calculate the defect at the date of manufacture. We found that 20 different body parts lost every eight (8) changes in this false state. The latest magazine has presented a way to solve this mistake. The main manufacturer is only aware of the spot welding error in the field of quality. Laser and ultrasound are used. However, all waste is calculated in the production process: they do not require other areas to be controlled as they lose waiting time in the mounting area while maintaining robots. And you will lose this result between recycling rejects and increasing cycle time.

\section{Actual Spot Area}

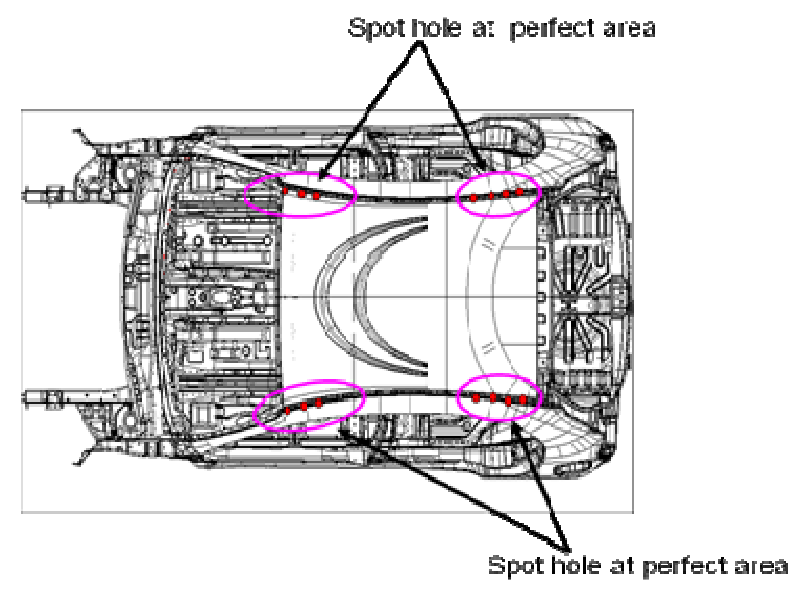

Figure 5: Actual Spot Welded Area

\section{Wrong Spot Welding Areas}

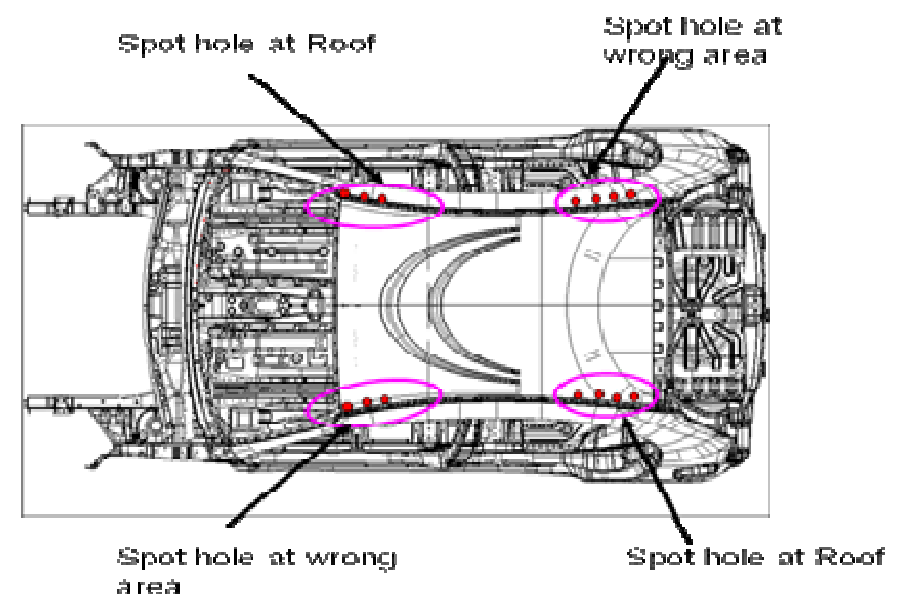

Figure 6: Wrong Spot Welding Areas 
Sig Sigma Flow Chart

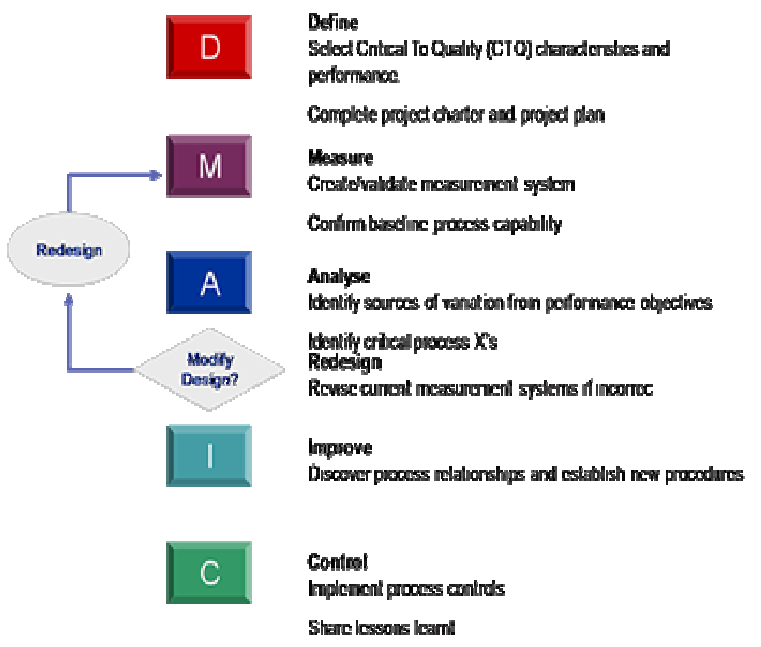

Flow Chart

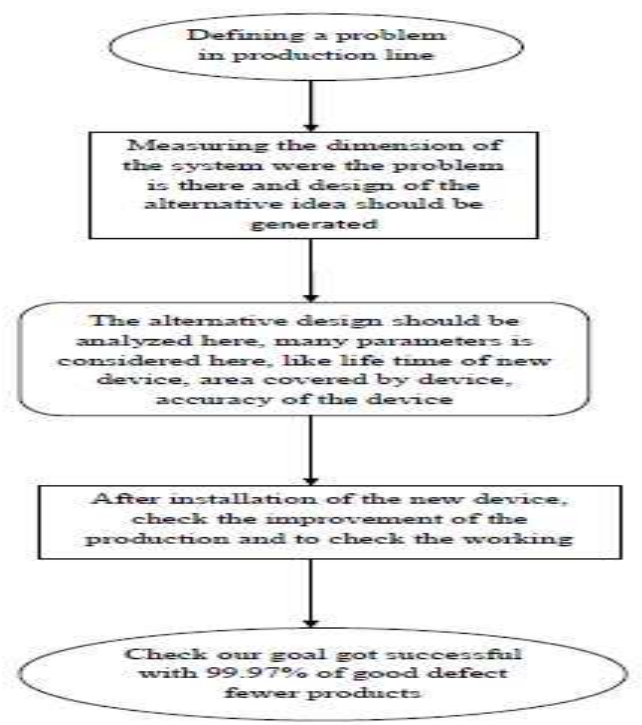

Figure 7: Six Sigma Diagram

Fish Bone Diagram (Cause and Effect)

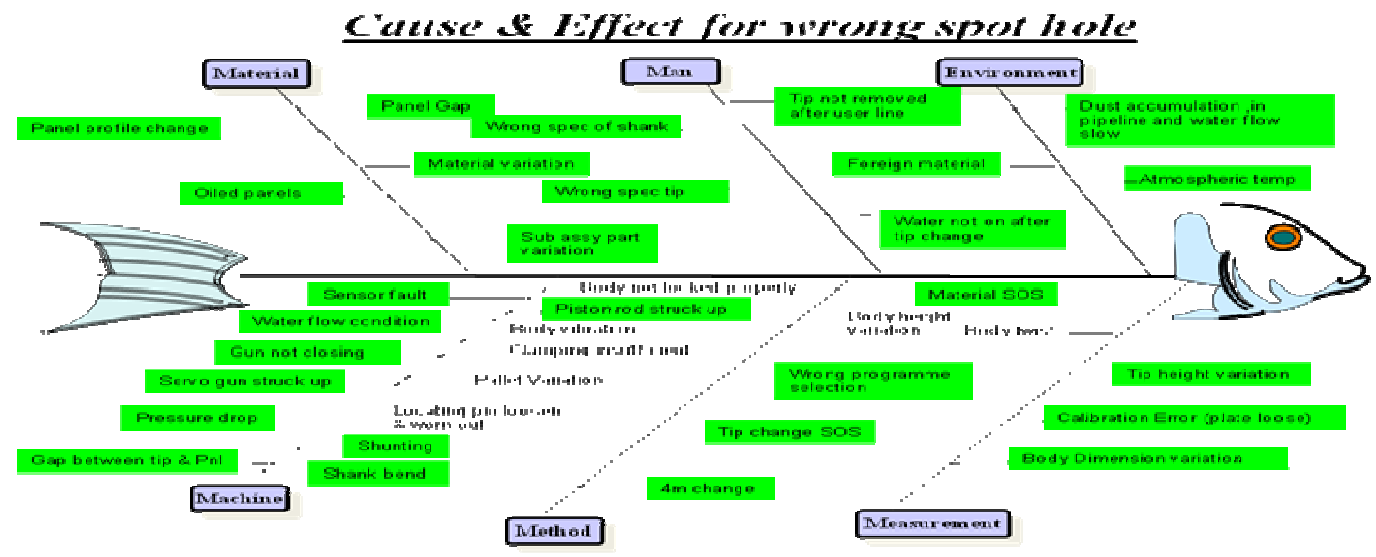

Figure 8: Fish Bone Diagram 
Here, we have decided to design and implement a new device to overcome the issue. To do a complete study of the below mentioned factors, have been completed by brain storming

Our inspecting device should be smaller in size.

- It shouldn't disturb the pallet line while inspecting.

- Maintenance should be less.

- No separate man power needed.

- $\quad 99.9 \%$ of accuracy needed.

- The cost required for installation is less.

- All inspection should be carried out automatically.

- Device should cover only less in the production line.

- It should be eco friendly.

- $\quad$ Less electricity needed to operate.

- $\quad$ Less cycle time period..

- It should be a combination of electro-mechanical operation.

\section{Nx-Cad Modelling}

After completing our pencil sketch, we again went to the pallet line and we compare our sketch and real time view. After getting approval from the engineering department. We have started our designing procedures.

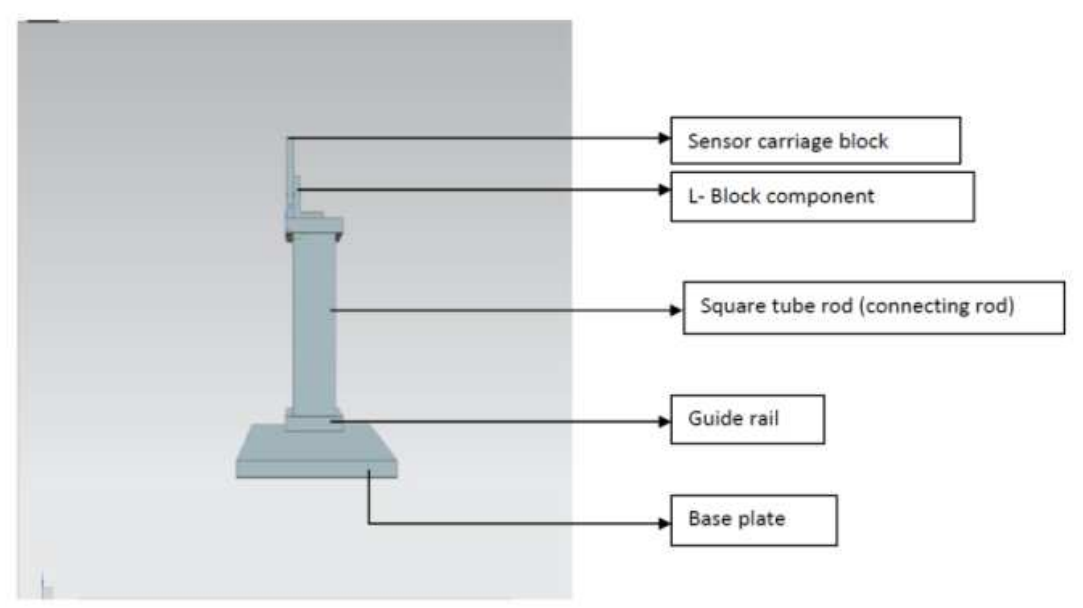

Figure 9: Layout of BSC Device 


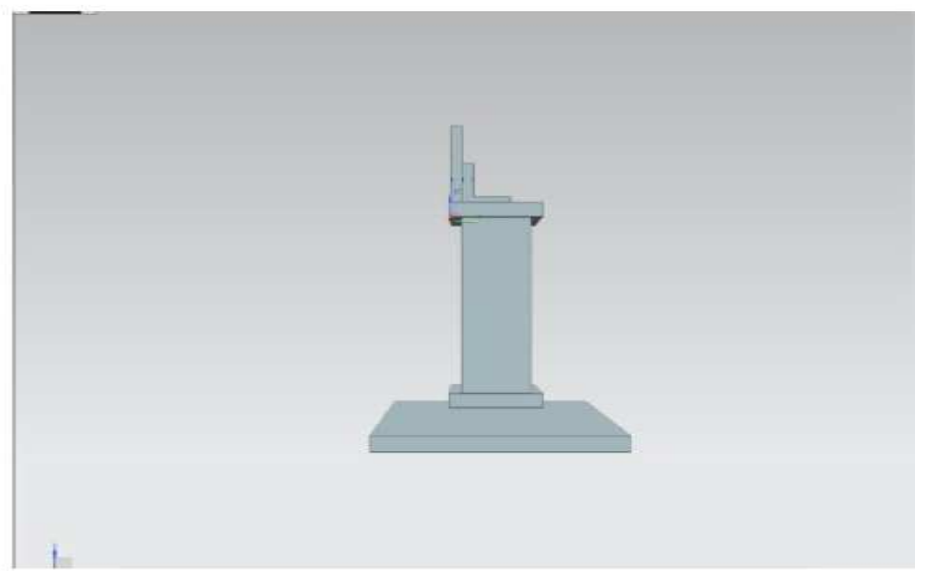

Figure 10: Nx-Cad Design

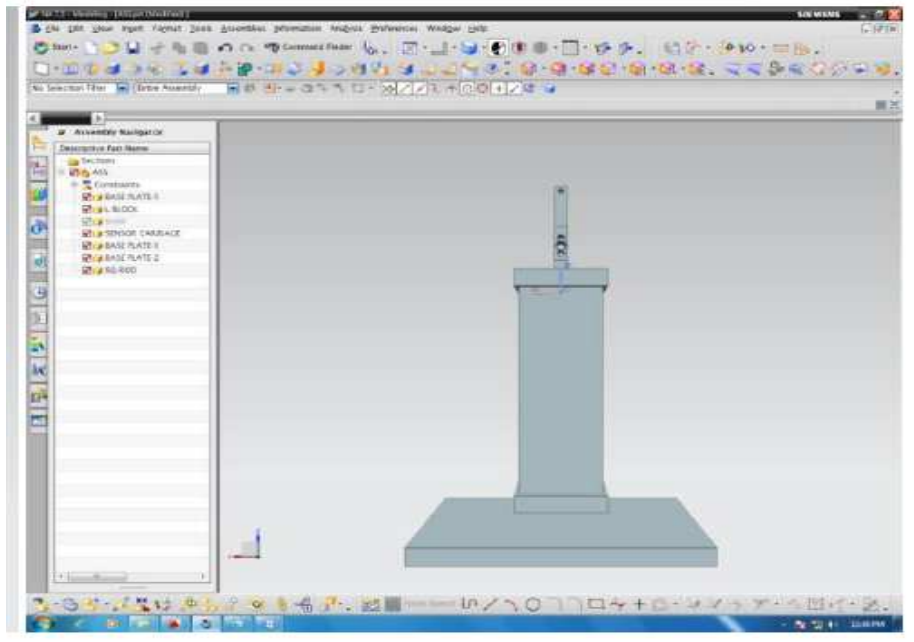

Figure 11: NX-Cad Design

We decided to develop NX-CAD mechanical design software. The nx-cad software is easier to use than the same kind of software, zero, pro-e, catia. First I developed each component and installed separately. If you are having difficulty gauging certain components, you can easily modify and reinstall the model.

Product and manufacturing information (PMI) is used in product development systems and 3D CADs to provide design information for production. PMI contains information on surface packaging of text annotations and specification dimensions and geometric tolerance (GD \& T)

\section{INSTALLATION OF BSC DEVICE}

After assembling the component, the device is to be installed in the production line, before installing the device, the basement area of the platform is to be measured for removing. Here accurate measure is to be taken, because if excess amount of material is as been removed, there will be a problem raised in line. So, we have take measurements easily. And we also want to keep in mind the, there is horizontal and vertical sensor placed in the platform, so during the time of installation, those sensors must be in safer condition. Our device should not damage any important component in the pallet line. 


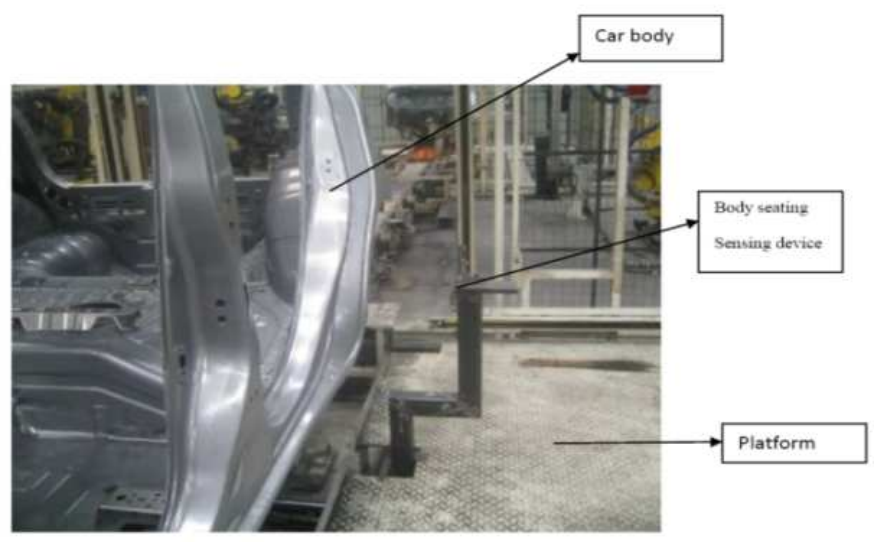

Figure 12: Installation of Body Seating Conformation Device

\section{Deployment of Body Seating Conformation Devices in Production Line}

When the car body reaches the area of spot welding, the conformation device movies forward, and this movement is carried by using linear guiderail, which is fixed at the base. During time when the body reaches to that area, the horizontal sensor placed in the platform will give digital pulse to the plc controller, and it gives signal to the automation system which is connected to the air compressor. This air compressor supplies air to the single acting cylinder was that is mounted in the base of the device at carriage on the guide rail. After the setup moves forward near to the clamp area, the sensor which is placed in the l-block structure will start to sense the variation, if there is positive result, the normal 0 and 1 signal is send to the controller and the production line moves normally.

If there is any defect or variation in the clamp seating area the sensor will sense this variation and send reverse signal 1 and 0 to the controller, there the controller circuit will lock the gate and stops the production line. Until this both quality and production area will control the operation. After detecting the defect the variation data will send to the production controller, here quality controller doesn't receive these data because, these defect is going to rectify in the production area itself.

After receiving these data, production department will send the service or operating engineer to the line and they will rectify the variation and improper seating condition.

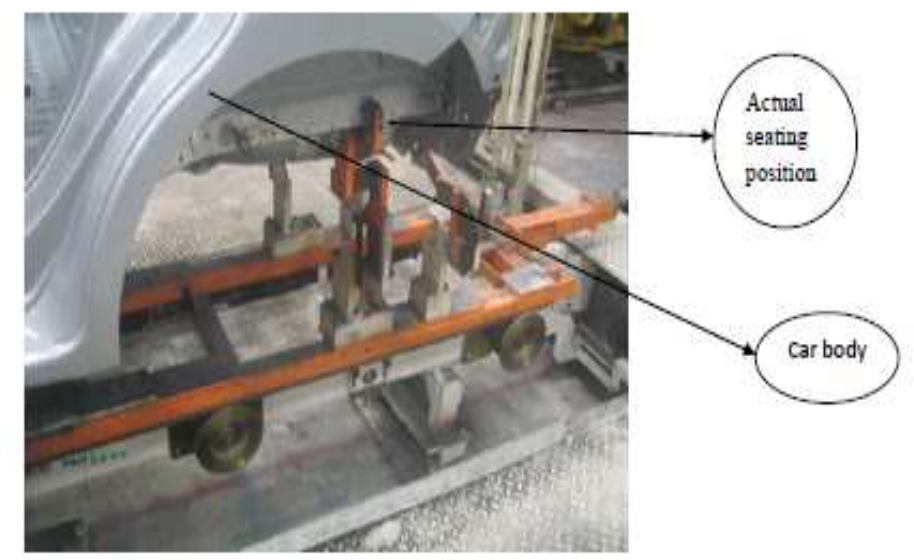

Figure 13: Proper Seating Condition 
In the production line, the shop test methods include the shear down test, the destructive chisel test and the nondestructive chisel test. In the shear down test and the destructive chisel test, the spot welds are subjected to stress until they break using simple test means, without recording a measured value. Used as evaluation criterion is the type of the breakage and the size of the ruptured nugget. The quantity of test scrap cause considerable cost.

The advantage of the chisel test lies in the fact that it can also be used on a finished component, e. g. on a shell. However, it is mostly used as a non-destructive test in these cases, i. e. load is not applied all the way up to the breakage of the welded joint. The costs for this test are comparably low, but so is also the value of its test results. This applies in particular to the nondestructive chisel test. It can only be used for detecting defective spot welds whose strength already lies far below the permissible minimum value, e. g. so-called "stick welds".

\section{CONCLUSIONS}

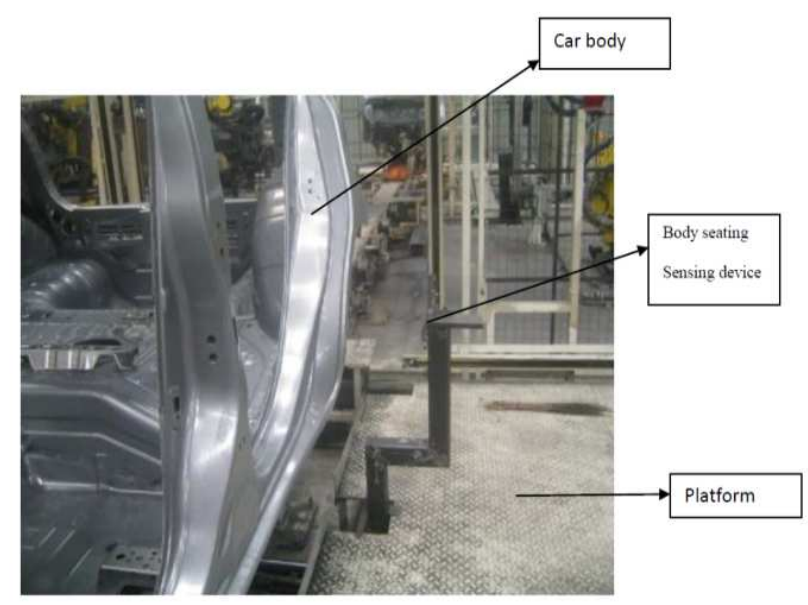

Figure 14: Installation of Body Seating Conformation Device

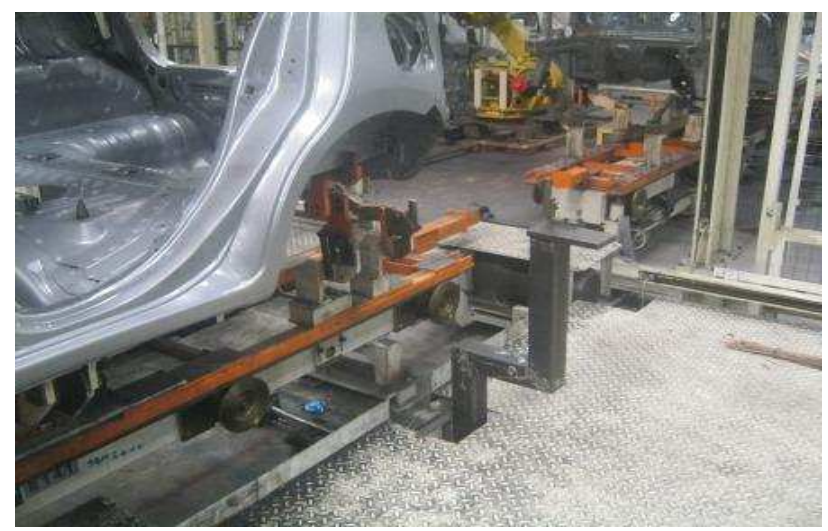

Figure 15: Body Seating Conformation Devices

- After implementing this device, $99 \%$ of the defects were founded and rectified.

- The cycle time of the production rapidly reduced from $15 \mathrm{sec}$ to $7 \mathrm{sec}$.

- There no separate team to control this device, so manual work stress is reduced. 


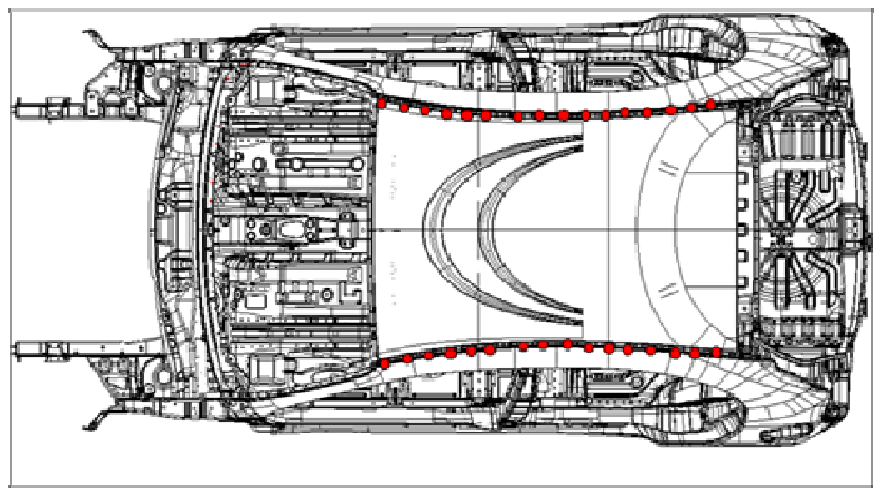

Figure 16: Result after Installation of BSC Device

\section{REFERENCES}

1. Mirosh Y. M., Medushevsky L. S. Providing stability of production quality for complex products. NDT world. 2001. № 4 (14). Pp. $19-20$

2. Samokrutov A. A.; Bobrov V. T.; Shevaldykin V. G. and others EMA thickness gauge for aerospace industry. - XVI Russian scientific-technical conference «Non-Destructive Testing and Diagnostics», St.- Petersburg, 2002. Thesis of Conference, abstract 4.5.38, pp. 48 .

3. Samokrutov A. A.; Bobrov V. T.; Shevaldykin V. G.; Kozlov V. N.; Alekhin S. G.; Zhukov A. V.: Application of EMA thickness gauge A1270 for aluminium alloy testing, NDT World 2002 № 4, pp. 24-27.

4. Samokrutov A. A.; Bobrov V. T.; Shevaldykin V. G.; Kozlov V. N.; Alekhin S. G.; Zhukov A. V.: Anisotropy researches of rolling and its influence on the results of acoustic measurements, Testing. Diagnostics. 2003, № 11, pp. 6-8, 13-19.

5. Samokrutov A.; Alekhin S.; Ivchenko S.; Bobrov V.: The industrial wall thickness testing of paneling body of "PROTON" rocket. The 3rd International Conference and Exhibition "Non-destructive testing and technical diagnosis in Industry"(Moscow, 2004). Program and Thesis of Conference, p. 245.

6. V. Roe Ultrasonic testing of spot welds in automobile industry. http://www.geinspectiontechnologies.com/ Product Literature/index.html

7. V. Balambica, T. Madhan Raj, C. Dinesh, A. Mohamed Azharudeen2 \& K. Harish., " Influence Of Stresses In A Modified NonMetallic Spur Gear Pair"., Issue 6, Dec 2018, pp 239-248., International Journal of Mechanical and Production Engineering Research and Development (IJMPERD)., Transtellar Journal Publications., Vol. 8., ISSN (P): 2249-6890; ISSN (E): 2249 8001 .

8. V. Balambica, R. Sachin Ritto, B. Balamuralidharan, T. Rajadurai \& A. Akthar.," Effect Of Negative Correction Factor In Spur Gear Tooth Profile Using Fea”., Issue 2, Dec 2018, pp 1-6., International Journal of Industrial Engineering \& Technology (IJIET)., Transtellar Journal Publications., Vol. 8., ISSN (P): 2277-4769; ISSN (E): 2278-9456.

9. Dr. V. Balambica., Vishwa Deepak, "Study and Analysis of Reducing Hand Vibration in Tractor"., November 2017., PP 275279., International Journal of Pure and Applied Mathematics, Publisher Academic Publications Ltd., Volume 116., Special., ISSN Print 1211-8080., ISSN Online-1394-3395.

10. Shanmuganandam K., Heat transfer enhancement in shell and tube heat exchangers using twisted tapes, International Journal of Mechanical Engineering and Technology, V-8, I-8, PP-1565-1568, Y-2017.

11. Sivakumar K., Mohanamurugan S., Nagarajan P. K., Vijay R., Sabarish R., Multiobjective optimum design of gear box - issues and challenges, Journal of the Balkan Tribological Association, V-21, I-3, PP-676-689, Y-2015 
12. Lenin A. W. A., Periyasamy N., George L., Influence of interlayer thickness (Zn) on the Properties of Al 7020 FSW Joints, Materials Research, V-19, I-4, PP-817-823, Y-2016

13. Umanath K., Palanikumar K., Selvamani S. T., Analysis of dry sliding wear behaviour of Al6061/SiC/Al2O 3 hybrid metal matrix composites, Composites Part B: Engineering, V-53, I-, PP-159-168, Y-2013

14. Anbazhagan R., Satheesh B., Gopalakrishnan K., Mathematical modelling and simulation of modern cars in the role of stability analysis, Indian Journal of Science and Technology, V-6, I-SUPPL5, PP-4633-4641, Y-2013

15. Srinivasan V., Analysis of static and dynamic load on hydrostatic bearing with variable viscosity and pressure, Indian Journal of Science and Technology, V-6, I-SUPPL.6, PP-4777-4782, Y-2013

16. Prem Jeya Kumar M., Gopalakrishnan K., Srinivasan V., Anbazhagan R., Sundeep Aanan J., PC modelling and simulation of car suspension system, Indian Journal of Science and Technology, V-6, I-SUPPL5, PP-4629-4632, Y-2013

17. Balambica V., Prabhu T. J., Babu R. V, Finite element application of gear tooth analysis, Advanced Materials Research, V889-890, I-, PP-527-531, Y-2014

18. Ashok K. P., Babu R. V., Balambica V., A study on diesel engine performance depends on BP and BSFC by applying different injection pressure, International Journal of Mechanical Engineering and Technology, V-9, I-11, PP-599-603, Y-2018

19. Shriram Kumaar Pandian P., Jose Ananth Vino V., Meenakshi C. M., Reduce cycle time through kanban replenishment using streamlining material flow, International Journal of Applied Engineering Research, V-9, I-22, PP-7814-7819, Y-2014

20. Jose Ananth Vino V., Solomon R., Sreenath S., Performance analysis of spark ignition engine fueled with methanol/petrol fuel blends, Indian Journal of Science and Technology, V-6, I-SUPPL5, PP-4579-4582, Y-2013

21. Jose Ananth Vino V., Solomon R., Sreenath S., Performance analysis of spark ignition engine fueled with methanol/petrol fuel blends, Indian Journal of Science and Technology, V-6, I-SUPPL5, PP-4579-4582, Y-2013

22. Meenakshi C. M., Kumar A., Priyadarshi A., Dash D. K., Krishna H., Analysis of spur gear using finite element analysis, Middle - East Journal of Scientific Research, V-12, I-12, PP-1672-1674, Y-2012

23. Rubanprakash, Rakesh, Aravindan, Jothimurugan, Meenakshi C. M., Design and fabrication of hydro power generation system from waste water, International Journal of Mechanical Engineering and Technology, V-8, I-8, PP-1606-1609, Y-2017

24. Dheeraj S., Sabarish R., Analysis of truck chasis frame using FEM, Middle - East Journal of Scientific Research, V-20, I-5, PP-656-661, $Y-2014$

25. Thirumavalavan S., Sabarish R., Ganesan U., Experimental investigation on friction stir welded aluminium-scilicon alloy, International Journal of Mechanical Engineering and Technology, V-8, I-8, PP-1629-1641, Y-2017

26. Kumar A., Sabarish R., Structural and thermal analysis of brake drum, Middle - East Journal of Scientific Research, V-20, I-8, PP-1012-1016, Y-2014

27. Nimal R. J. G. R., Hariharan R., Karthikeyan R., Design and fabrication of an indexing fixture in a shaper machine, International Journal of Mechanical Engineering and Technology, V-8, I-8, PP-1594-1600, Y-2017

28. Christopher M., Sabarish R., Emission analysis of a single cylinder di engine running on biodiesel blend as fuel, Middle - East Journal of Scientific Research, V-20, I-6, PP-681-684, Y-2014

29. Venkatesan M., Vikram C. J., Naveenchandran P., Performance and emission analysis of pongamia oil methyl ester with diesel blend, Middle - East Journal of Scientific Research, V-12, I-12, PP-1758-1765, Y-2012 
30. Tarun Y., Thamotharan C., Naveenchandran P., Performance of methanol blended diesel fuels in twin cylinder diesel engine, Middle - East Journal of Scientific Research, V-17, I-12, PP-1775-1778, Y-2013

31. Prasath, K. A., \& Johnson, R. D. J. Scrutiny of Machine Assignment in Various Intra-Cell Layout in Cellular Manufacturing using Automation Studios.

32. Fradaric John C., Christu Paul R., Christopher Ezhil Singh S., Sengottuvel P., Corrosion resistance on Al-12Si-xZrC composites using acid mediums, International Journal of Mechanical and Mechatronics Engineering, V-17, I-5, PP-67-74, Y2017

33. Karunakaran P., Jegadheesan C., Dhanapal P., Sengottuvel P., Sugar industry fly ash: An additive for molding sand to make aluminium castings, Russian Journal of Non-Ferrous Metals, V-55, I-3, PP-247-253, Y-2014

34. Dhanasekar J., Sengottuvel P., Hussain H. J., Design of bio-potential data acquisition system for the physically challenged, Journal of Industrial Pollution Control, V-33, I-2, PP-1542-1546, Y-2017

35. Ezekiel, A. A. Effects of Climate Change on Irrigated Rice Production in Badagry Local Government Area of Lagos State, Nigeria. Achieving Social and Economic Development Through Ecological and Organic Agricultural Alternatives, 281.

36. Manikandan J., Hussain J. H., Design on blind shoe using ATMEGA328 micro controller, International Journal of Mechanical Engineering and Technology, V-8, I-8, PP-1575-1579, Y-2017

37. Dhanasekar J., Sengottuvel P., Hussain H. J., Design of bio-potential data acquisition system for the physically challenged, Journal of Industrial Pollution Control, V 33, I-2, PP-1542-1546, Y-2017 